\title{
Performance Evaluation of Throughput MAXIMIZATION TECHNIQUE IN MC-CDMA FOR 4G STANDARD
}

\author{
Hema Kale ${ }^{1}$ C.G. Dethe ${ }^{2}$ and M.M. Mushrif ${ }^{3}$ \\ ${ }^{1}$ ETC Department, Jhulelal Institute of Technology Nagpur, India. \\ hema.kale72@gmail.com \\ ${ }^{2}$ ECE Department, Priyadarshni Institute of Engineering and Technology, \\ Nagpur, India. \\ cgdethe@yahoo.com \\ ${ }^{3}$ ETC Department, Yashwantrao Chavan College of Engineering, Nagpur, India \\ milindmushrifayahoo. com
}

\begin{abstract}
Efficient resource allocation is the major issue in the development of fourth generation mobile communication systems. A very high data rate is needed for advanced multimedia applications and internet. This paper evaluates the performance of improved algorithm for the future Long Term Evolution (LTE) advanced standards-the 3GPP candidate for 4G. For the analysis autoregressive model of correlated Rayleigh fading processes is used. Simulation results shows that for downlink transmission a very high data rate, upto hundreds of Mbps can be obtained using improved algorithm under the constraints of available transmit power and given BER. Same algorithm is also analysed by varying the no. of users and spreading factor. Performance of the improved algorithm is evaluated in comparison with ACA algorithm and shows significant improvement in the throughput for the three combining schemes.
\end{abstract}

\section{KEYWORDS}

LTE, MC-CDMA, Autoregressive model, SNR, BER, ACA,CSI .

\section{INTRODUCTION}

To support the time varying QoS in multiuser environment for 4G systems multicarrier CDMA (MC-CDMA) is the strong candidate.In this paper Spectrum allocation technique for MC-CDMA systems is evaluated for LTE advanced standard and channel model is Rayleigh fading channel model.In Release 10, Long Term Evolution (LTE) advanced was stan-dardized by 3GPP as the successor of the Universal Mobile Telecommunication System (UMTS) and LTE. The targets for downlink and uplink peak data rate requirements were set to $1 \mathrm{Gbit} / \mathrm{s}$ and $500 \mathrm{Mbit} / \mathrm{s}$, respetively, when operating in a $100 \mathrm{MHz}$ spectrum allocation.

Improved algorithm for throughput maximization in MC-CDMA is proposed in [1]. Channel fading is different at different subcarriers, this feature has been exploited for allocating the subcarriers to the users according to the instantaneous channel state information (CSI) in [1] and [2]. In [2] an Adaptive Channel Allocation (ACA) algorithm is proposed for maximizing throughput in which the subchannels are divided in to groups, and these groups are allocated to the users depending on required transmit power. This is a contiguous channel allocation in which channel fading feature is not fully exploited. 
Various subcarrier selection techniques are discussed in [3] by dividing the spectrum allocation techniques in two broad categories i.e. single channel allocation and group of channel allocation. The SCS-MC-CDMA system assigns to each user a selected number of sub-carriers [5]. The concept of sub-carrier selection is introduced to counter the problem of high power consumption. In this paper the concept is to assign each user only as many sub-carriers as are needed to support the user's data rate. In this method the system complexity increases when more number of filters are required for subcarrier selection. Instantaneous CSI refers to the amount of channel fading user experiences on particular channel. Some schemes have been proposed for subcarrier selection according to CSI which includes, Selecting the subcarrier receiving maximum power on it, Selecting the sub-carrier with maximum SNR, Selecting the subcarrier requiring least amount of transmit power on it.In this paper last one has been discussed for achieving optimum throughput.

An appropriate sub-carrier selection technique results in high spectrum efficiency, reduction in high power consumption at the mobile terminal, high data throughput in a multicell environment, improvement in BER performance, reduction in signal processing at the mobile terminal.

For the given power, throughput can be maximized by assigning maximum number of subcarriers to the users.

In [6] Qingxin Chen, Elvino S. Sousa and Subbarayan pasupathy proposed a Water-filling algorithm, it was motivated by the water-filling (WF) principle in information theory, it improves the speed and average SINR of the system. One drawback lie in the case where one user's fading amplitudes are much larger than the average. G.K.D.Prasanna Venkatesan, and C.Ravichandran, has suggested a dynamic sub-carrier allocation technique for adaptive modulation based MCCDMA system in [7] which results in improvement in throughput and BER performance. In this paper water filling algorithm is used to select the best sub-carrier, over the existing subcarriers. In this the principle of adaptive modulation consists of allocating many bits to carriers with a high SNR, whereas on carriers with low SNR only a few or no bits at all are transmitted. However there will be a possibility that when many channels suffer deep fading, there will be no transmission or very few bits are transmitted. If subcarrier selections techniques are combined with adaptive modulation techniques further improvement in data rate is resulted as discussed in [8]. In [8] modulation scheme changes with change in no. of users satisfying the BER requirement.

In this paper we investigate the method of subchannel allocation to the user for the given transmit power in the downlink transmission. According to CSI each user will require a different transmit power on each channel, using this characteristic group of channels will be allotted to users. In the proposed algorithm [1] the method of group allocation to the users has been modified which will result in producing global minima. This will result in further saving of the power and higher throughput as compared with the ACA algorithm[2].

In section 2 problem of throughput maximization in the downlink for MC-CDMA is considered, In section 3 Improved algorithm of subchannel allocation to the users is presented. Then Numerical results are discussed by considering simulation environment of LTE-A standards in section 3. At the end conclusions are drawn in section 4.

\section{THROUGHPUT MAXIMIZATION PROBLEM}

\section{Problem Formulation}

We have to make optimum use of the resources i.e. channels and transmit power to maximize the throughput. In the downlink transmission of multiuser MC-CDMA technique for the given 
transmit power at the base station maximum possible number of channels should be allocated to the users to maximize throughput maintaining low BER.

If the required amount of transmit power of each channel has been determined for all users before the channel allocation, then throughput maximization problem is given by a following optimization of $c_{\mathrm{g}}^{\mathrm{u}}$ problem as [2],

$$
\max \sum_{\mathrm{u}=1}^{\mathrm{U}} \sum_{\mathrm{g}=1}^{\mathrm{G}} \mathrm{c}_{\mathrm{g}}^{\mathrm{u}}
$$

Where

$c_{\mathrm{g}}^{\mathrm{u}}$ - number of the uth user's channels on the gth group.

$\mathrm{U}$ - Total number of users

$\mathrm{G}$ - Total number of groups of subcarriers.

Problem (1) is subject to

$$
\begin{gathered}
\sum_{\mathrm{u}=1}^{\mathrm{U}} \operatorname{sgn}\left(\mathrm{c}_{\mathrm{g}}^{\mathrm{u}}\right) \leq 1, \quad \forall \mathrm{u}, \mathrm{g} \\
\sum_{\mathrm{u}=1}^{\mathrm{U}} \sum_{\mathrm{g}=1}^{\mathrm{G}} \mathrm{c}_{\mathrm{g}}^{\mathrm{u}} \\
\mathrm{c}_{\mathrm{g}}^{\mathrm{u}} \in\{0,1, \ldots, \mathrm{S}\}, \quad \forall \mathrm{u}, \mathrm{g}
\end{gathered}
$$

Where

$\mathrm{S}$ - Total number of subcarriers in gth group.

Above equation (1.b) is the total transmit power constraint.

where

PT max - The maximum transmit power, and $\mathrm{pg}_{\mathrm{g}}^{\mathrm{u}}$ - The required transmit power for uth user on one channel of the gth group, it is expressed as,

$$
p_{g}^{u}=\beta N_{o} S^{-2} \sum_{s=1}^{S}\left|\omega_{g, s}^{u}\right|^{2} \sum_{s=1}^{S}\left|\omega_{g, s}^{u} f_{g, s}^{u}\right|^{-2}
$$

Where

$\beta$ - Target threshold of BER.

$\mathrm{f}_{\mathrm{g}, \mathrm{s}}^{\mathrm{u}}-\mathrm{uth}$ user's channel fading on the sth subcarrier of the desired group

$\omega_{\mathrm{g}, \mathrm{s}}^{\mathrm{u}}-\mathrm{uth}$ user's frequency domain combining weight for the signal on the sth subcarrier of the desired group.

Therefore the problem of throughput maximization can be put forward as, Every user experiences different fading on different channels and consequently user requires different transmit power on different channels. For the given system we have to form groups of neighbouring channels and then these groups are allocated to the users according to the transmit power requirement. 
International Journal of VLSI design \& Communication Systems (VLSICS) Vol.3, No.6, December 2012

\section{SUbChANNEL SELECTION-IMPROVED ALgORITHM}

An improved algorithm is proposed in [1] for the channel allocation in the downlink transmission of multi-user MC-CDMA systems for throughput maximization, under the constraints that the total transmit power should not exceed the maximum transmit power and each channel's SINR should not be less than a pre-defined value.

In this algorithm a subchannel group assignment technique is suggested as below,

\subsection{Criteria used for group allocation}

In this scheme, the group of subchannels are allocated to the different users by,

1) Calculating required transmit power for the users on one channel of all groups.

2) while allocating groups to the users, all the G number of groups will scan all the U number of users at the same time and the user requiring minimum transmit power calculated as per (1) is allocated that group.

3) Next remaining (G -1) number of groups will scan all the remaining (U -1) number of users and so on.......

The improved algorithm [1] is as follows,

Initialization

$\mathrm{P}_{\mathrm{R}}=\mathrm{P}_{\mathrm{T}}^{\mathrm{max}}, \mathrm{C}=\{1,2, \ldots, \mathrm{G}\}, \mathrm{c}_{\mathrm{g}}^{\mathrm{u}}=0$ for

$\mathrm{u}=1, \ldots, \mathrm{U}$ and $\mathrm{g}=1, \ldots, \mathrm{G}$.

Group assignment

while $\mathrm{C} \neq \varnothing$

$\mathrm{u}=1: \mathrm{U}$

$\mathrm{g}=1: \mathrm{G}$

$\left[p_{\min }, u_{\text {gmin }}\right]=\min \left(\min \left\{p_{g}^{u}\right\}\right) \%$ allocate a group to user requiring least power on one channel of that group

end

Channel allocation

while $\mathrm{C} \neq \varnothing$

$\mathrm{t}=\arg \min _{\forall \mathrm{g} \in \mathrm{C}}\left\{\mathrm{p}_{\mathrm{g}}^{\mathrm{u}_{\mathrm{gmin}}}\right\} ; \%$ select the group with

lowest power requirement

$c_{t}^{u_{t \min }}=\min \left(\left\lfloor\frac{P_{R}}{p_{t}^{\mu_{t \min }}}\right\rfloor, S\right) ; \%$ calculate the available

channel number

$\mathrm{P}_{\mathrm{R}}=\mathrm{P}_{\mathrm{R}}-\mathrm{c}_{\mathrm{t}}^{\mu_{\mathrm{tmin}}} \mathrm{p}_{\mathrm{t}}^{\mu_{\mathrm{tmin}}} ; \%$ calculate the residual

transmit power

$\mathrm{C}=\mathrm{C} \backslash\left\{\mathrm{u}_{\mathrm{tmin}}\right\}$

If $\mathrm{c}_{\mathrm{t}}^{\mu_{\mathrm{tmin}}}=0 \%$ since the residual transmit power is not

enough , terminate channel allocation.

Break the loop;

End If

End While

Different combining schemes will result in different power allocation, accordingly required transmit power $\left(\mathrm{p}_{\mathrm{m}}^{\mathrm{k}}\right)$ will change.Frequency domain combining weights for MRC, EGC and ZFC scheme are as per Table1. Therefore throughput will be different for different combining schemes 
International Journal of VLSI design \& Communication Systems (VLSICS) Vol.3, No.6, December 2012

Table1

Frequency Domain Combining Weight [9]

\begin{tabular}{|c|l|l|l|}
\hline & \multicolumn{3}{|c|}{ Combining Schemes $\left(\omega_{\mathrm{g}, \mathrm{s}}^{\mathrm{u}}\right)$} \\
\hline Channel Fading & MRC & EGC & ZFC \\
\hline $\mathrm{f}_{\mathrm{g}, \mathrm{s}}^{\mathrm{u}}$ & $\left(\mathrm{f}_{\mathrm{g}, \mathrm{s}}^{\mathrm{u}}\right)^{*}$ & $\left(\mathrm{f}_{\mathrm{g}, \mathrm{s}}^{\mathrm{u}}\right)^{*} /\left|\mathrm{f}_{\mathrm{g}, \mathrm{s}}^{\mathrm{u}}\right|$ & $\left(\mathrm{f}_{\mathrm{g}, \mathrm{s}}^{\mathrm{u}}\right)^{*} /\left|\mathrm{f}_{\mathrm{g}, \mathrm{s}}^{\mathrm{u}}\right|^{2}$ \\
\hline
\end{tabular}

\section{Performance evaluations}

Here the computer simulations are carried for the simulation environment selected to meet the specifications of LTE-A standards. Long Term Evolution (LTE) advanced standards is the 3GPP candidate for 4G [5]. It is assumed that the channel state information (CSI) is available at the base station. Stationary channel gain samples are produced using the autoregressive model of correlated Rayleigh fading processes [10]. CSI is continuously changing with time correspondingly user experiences different fading (f) on different channels.

Here three comparisons are considered, First the improved algorithm proposed in [1] is compared with the ACA algorithm[2] in terms of throughput by varying the transmit power. Second by increasing the number of users gradually changes in throughput are compared and third again throughput comparison by varying the spreading factor.

Table 2.

Simulation parameters

\begin{tabular}{|c|c|}
\hline Parameter & Environment \\
\hline Carrier frequency (fc) & $5 \mathrm{GHz}$ \\
\hline Operating bandwidth & $100 \mathrm{MHz}$ \\
\hline Subcarrier spacing & $25 \mathrm{KHz}$ \\
\hline Peak spectrum usage efficiency & $30(\mathrm{~b} / \mathrm{s} / \mathrm{Hz})$ \\
\hline Maximum Doppler frequency & $462.96 \mathrm{~Hz}$ \\
\hline Receiver speed & $100 \mathrm{~km} / \mathrm{hr}$ \\
\hline Symbol rate & $64 \mathrm{ksymbols} / \mathrm{s}$ \\
\hline No. of channels & 1024 \\
\hline Target SINR & $-4 \mathrm{~dB}$ \\
\hline
\end{tabular}

Frequency domain combining weights will be different for different combining schemes and accordingly throughput will vary for Minimal ratio combining (MRC), Equal gain combining (EGC) and Zero force combining (ZFC) schemes [1].

In the first comparison simulations are carried out for the environment selected as in table 2. First combining scheme under consideration is minimum ratio combining (MRC). In Fig. 1, the throughput versus the maximum transmit power is depicted for the case when the spreading factor 
International Journal of VLSI design \& Communication Systems (VLSICS) Vol.3, No.6, December 2012 and the number of users are 32. The maximum transmit power is measured by MaxSNR $=$ $\mathrm{P}_{\mathrm{T}}^{\max }$

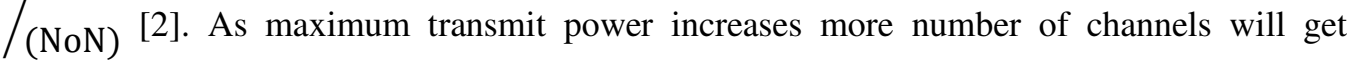

allocated to users for transmission and correspondingly throughput increases as shown in fig.1. Throughput obtained is in Megabits per second. Fig.2 and fig.3 shows throughput comparisons for improved algorithm [1] and ACA algorithm [2] for equal gain combining (EGC) and zero force combining (ZFC) schemes respectively. Since EGC and ZFC schemes have same required amount of transmit power for the one same channel, they give nearly the same throughput either improved or ACA scheme is applied.

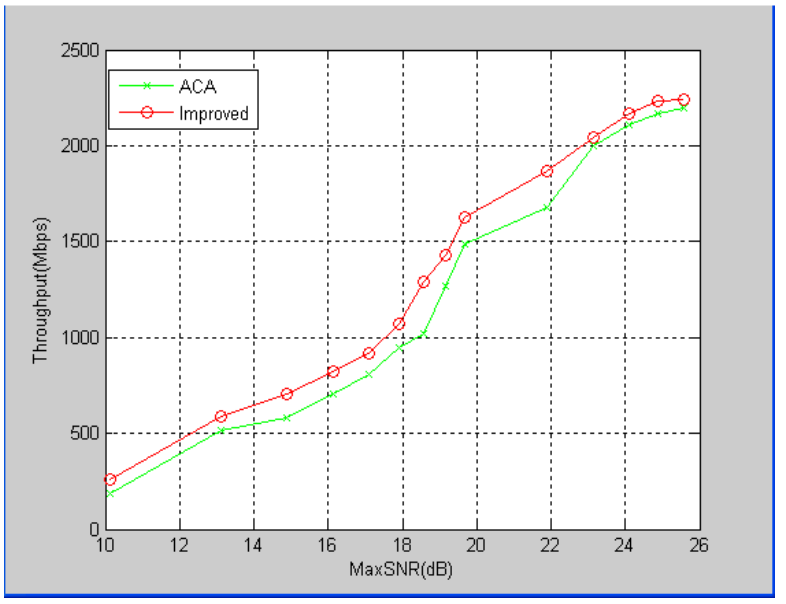

Figure.1 Throughput versus the maximum transmit power (measured by MaxSNR) for MRC scheme, when the spreading factor and the number of users are 32

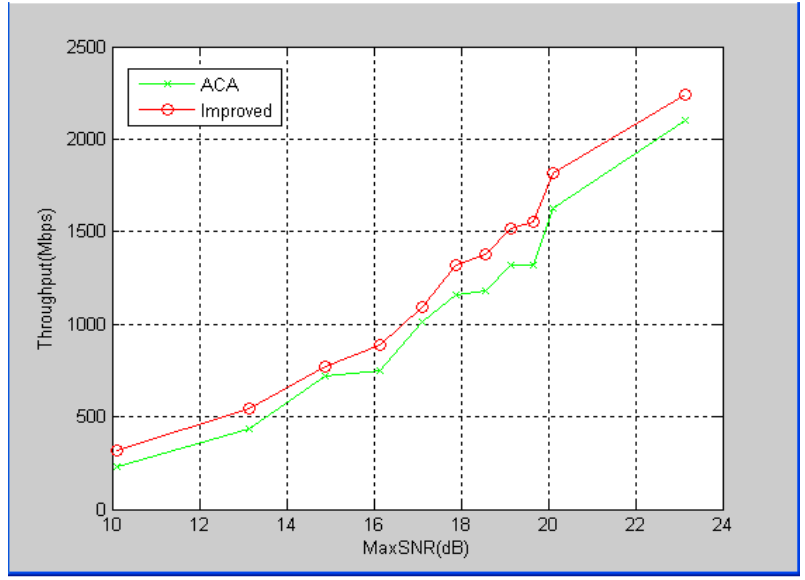

Figure 2 Throughput versus the maximum transmit power (measured by MaxSNR) for EGC scheme, when the spreading factor and the number of users are 32. 
International Journal of VLSI design \& Communication Systems (VLSICS) Vol.3, No.6, December 2012

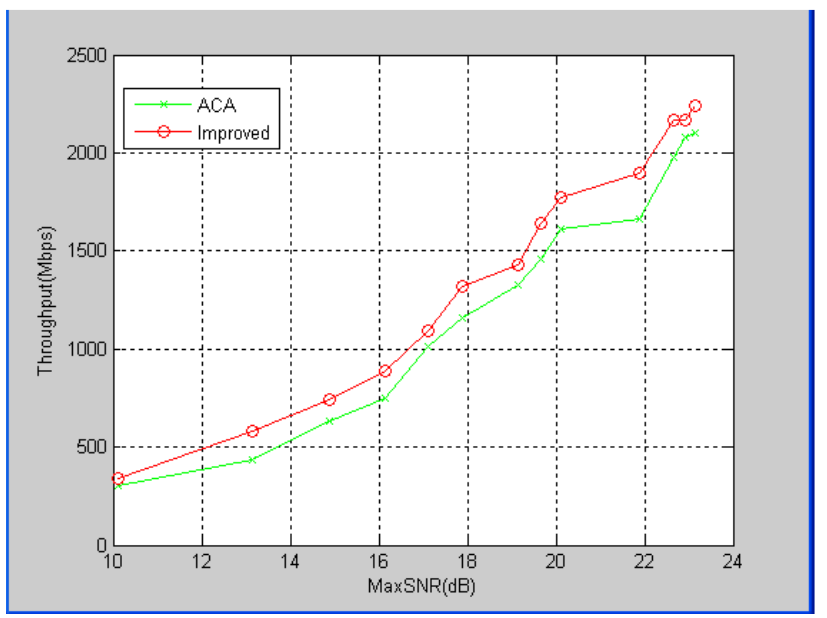

Figure 3 Throughput versus the maximum transmit power (measured by MaxSNR) for ZFC scheme. when the spreading factor and the number of users are 32 .

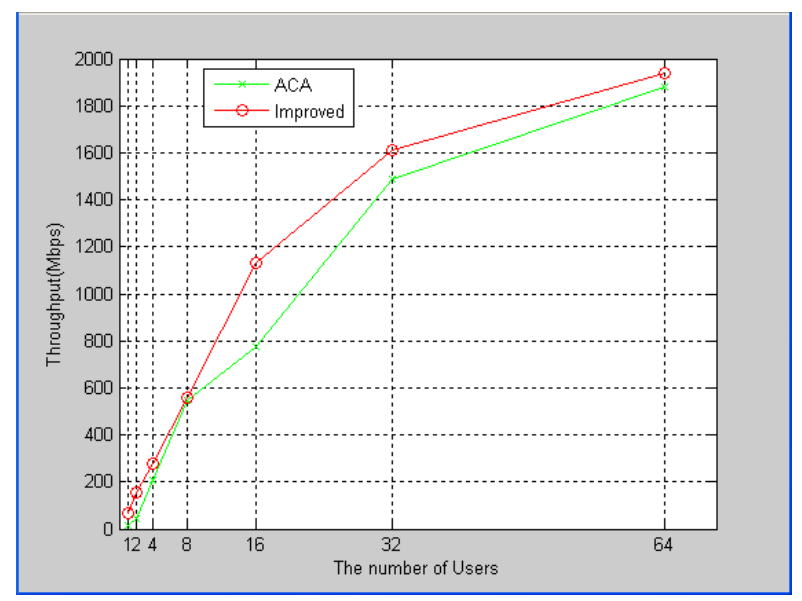

Fig.4 Throughput versus the number of users, when the spreading factor is 32, and the MaxSNR is $20.1198 \mathrm{~dB}$.

From the performance it can be seen that a very high data rate upto $2242.6 \mathrm{Mbps}$ is resulted when MaxSNR is $23.1301 \mathrm{~dB}$ for EGC and ZFC schemes which approaches the LTE advanced data rates. For all the three combining schemes Improved algorithm outperform ACA algorithm in terms of throughput.

Fig. 4 shows throughput variation with increase in the number of users when maximum transmit power, spreading factor and BER kept constant. It can be seen that as number of users increases group allocation to user scheme works in optimized manner as more number of users are available for scanning resulting in increase in throughput.

In another comparison a spreading factor is made variable keeping other factors constant as ,the number of users is 32, and the MaxSNR is 20.1198dB. Fig 5. shows the corresponding changes in throughput. As spreading factor increases the required amount of transmit power increases, resulting in decrease in throughput. 
International Journal of VLSI design \& Communication Systems (VLSICS) Vol.3, No.6, December 2012

In summary, the proposed Improved scheme in [1] outperform the ACA scheme in [2] in all areas mentioned above and can significantly improve the system performance in achieving a very high data rate required for latest $4 \mathrm{G}$ standard.

\section{CONCLUSION}

In this paper the performance of the improved algorithm for subcarrier allocation [1] is evaluated for the latest 3GPP release 10 LTE-A standards. The channel model considered is Rayleigh fading channel model.The proposed algorithm in [1] suggest an adaptive group assignment technique that will result in the optimum utilization of the available transmit power at the base station for allocating maximum no. of channels to the users.The further improvement in the throughput can be made by adapting non contiguous spectrum allocation scheme.

\section{ACKNOWLEDGMENT}

For this work I am thankful for the support of Bharat Sanchar Nigam Limited (BSNL) R.T.T.C. Center, Mobile Switching Centre and C.T.O. office, Nagpur,India.

\section{REFERENCES}

[1] Hema Kale1, C.G. Dethe2 and M.M. Mushrif3, "Improved Algorithm for Throughput Maximization in MC-CDMA", International Journal of VLSI design \& Communication Systems (VLSICS) Vol.3, No.4, August 2012.

[2] Jun-Bo Wang b, Ming Chen a, Jiangzhou Wang a, "Adaptive channel and power allocation of downlink multi-user MC-CDMA systems" Computers and Electrical Engineering 35 (2009) 622-633 (Elsevier journal ).

[3] Hema Kale1, C.G. Dethe2 and M.M. Mushrif3, "A Review of Sub-Carrier Selection Techniques Employed in MC-CDMA System for 4G Networks", International Journal of Scientific and Research Publications, Volume 2, Issue 4, April 20122 ISSN 2250-3153.

[4] http://www.radio-electronics.com/

[5] Teruya Fujii, Noboru Izuka, Hiroyoshi Masui, and Atsushi Nagate,"A proposal of sub-carrier selecting MC-CDMA system for 4G systems", 2005 IEEE.

[6] Qingxin Chen, Elvino S. Sousa and Subbarayan Pasupathy "Multicarrier CDMA with adaptive frequency hopping for mobile radio systems" , IEEE journal on selected areas in communications, vol. 14, no 9, december 1996.

[7] G.K.D.Prasanna Venkatesan, and V.C.Ravichandran, "Performance analysis of dynamic sub-carrier allocation technique for adaptive modulation based MC-CDMA system", JCSNS International Journal of Computer Science and Network Security, VOL.7 No.2, February 2007.

[8] S. Chatterjee1, W.A.C. Fernando2, M.K. Wasantha1 "Adaptive Modulation based MC-CDMA Systems for 4G Wireless Consumer Applications", IEEE Transactions on Consumer Electronics, Vol. 49, No. 4, NOVEMBER 2003.

[9] Kaiser S. OFDM code-division multiplexing in fading channels. IEEE Trans Commun 2002;50:126673

[10] Kareem E. Baddour, Student Member, IEEE, and Norman C.Beaulieu, Fellow, IEEE “Autoregressive Modeling for Fading Channel Simulation".

[11] Jolly Parikh, Anuradha Basu, "LTE Advanced: The 4G Mobile Broadband Technology", International Journal of Computer Applications (0975 - 8887) Volume 13- No.5, January 2011 


\section{Authors}

Hema R. Kale Received her B.E. degree in Electronics Engineering from Govt. College of Engg. Amt.in 1993 and received her M. Tech. degree from Y.C.C.E , Nagpur.in 2003. Now she is pursuing $\mathrm{Ph}$. D. from Nagpur university. She is having total ten years of teaching experience in Engg. Colleges. She is presently working as a Assistant Professor in JIT, Nagpur. Her research area includes mobile communication, digital signal processing. Four papers published in international journal. Recently presented papers in IJAS conference, Paris,France and IEEE ANTS conference in Banglore. She is a Life member of ISTE.

Chandrasekhar G. Dethe received his M.Tech. degree in Electronics Engineering from VNIT, Nagpur. ,and received his Ph.D. degree from Amravati University., Amravati. He worked as an Assistant Professor at SSGM, College of Engineering Shegaon from 1999 to 2005, later on he joined as a professor at YCCE, Nagpur. He is currently working as a principal of PIET, Nagpur. His fileld of specialization includes digital communication, Data network, Signal Processing. His papers are published in $\mathrm{N}$ ational and International Journals including IEEE proceedings. He is a fellow of IE and IETE and Life member of ISTE.

M. M. Mushrif received BE and ME degree from Walchand college of Engineering, Sangli and $\mathrm{PhD}$ from IIT kharagpur. Presently he is working as Professor and Head of Electronics Engineering Department in Yeshwantrao Chavan College of Engineering, Nagpur. His research areas are Image processing, Computer Vision, Soft computing, Digistal Signal Processing. Currently he is working in the area of Medical Image Processing.He has published research papers in IEEE and Elsevier Journals and several international and National conferences. He has also contributed a book chapter in the book "Roughsets and Image Analysis" published by CRC Press. He is member of IEEE,
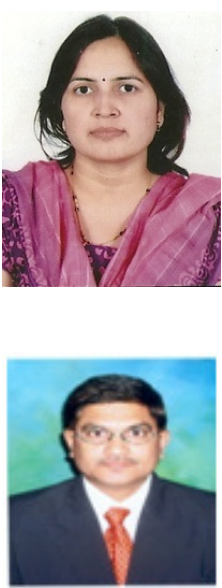
ISTE, IE and IAENG. 